\title{
Front Matter: Volume 8349
}

, "Front Matter: Volume 8349," Proc. SPIE 8349, Fourth International Conference on Machine Vision (ICMV 2011): Machine Vision, Image Processing, and Pattern Analysis, 834901 (30 January 2012); doi: 10.1117/12.924846

SPIE Event: Fourth International Conference on Machine Vision (ICMV 11), 2011, Singapore, Singapore 


\title{
PROCEEDINGS OF SPIE
}

\section{Fourth International Conference on Machine Vision (ICMV 2011 ) Machine Vision, Image Processing, and Pattern Analysis}

\author{
Zhu Zeng \\ Yuting Li \\ Editors \\ 9-10 December 2011 \\ Singapore \\ Organized by \\ Singapore Institute of Electronics \\ Sponsored by \\ International Association of Computer Science and Information Technology \\ Published by \\ SPIE
}


The papers included in this volume were part of the technical conference cited on the cover and title page. Papers were selected and subject to review by the editors and conference program committee. Some conference presentations may not be available for publication. The papers published in these proceedings reflect the work and thoughts of the authors and are published herein as submitted. The publisher is not responsible for the validity of the information or for any outcomes resulting from reliance thereon.

Please use the following format to cite material from this book:

Author(s), "Title of Paper," in Fourth International Conference on Machine Vision (ICMV 2011): Machine Vision, Image Processing, and Pattern Analysis, edited by Zhu Zeng, Yuting Li, Proceedings of SPIE Vol. 8349 (SPIE, Bellingham, WA, 2012) Article CID Number.

ISSN 0277-786X

ISBN 9780819490254

Published by

SPIE

P.O. Box 10, Bellingham, Washington 98227-0010 USA

Telephone +1 3606763290 (Pacific Time) · Fax +1 3606471445

SPIE.org

Copyright (C) 2012, Society of Photo-Optical Instrumentation Engineers

Copying of material in this book for internal or personal use, or for the internal or personal use of specific clients, beyond the fair use provisions granted by the U.S. Copyright Law is authorized by SPIE subject to payment of copying fees. The Transactional Reporting Service base fee for this volume is $\$ 18.00$ per article (or portion thereof), which should be paid directly to the Copyright Clearance Center (CCC), 222 Rosewood Drive, Danvers, MA 01923. Payment may also be made electronically through CCC Online at copyright.com. Other copying for republication, resale, advertising or promotion, or any form of systematic or multiple reproduction of any material in this book is prohibited except with permission in writing from the publisher. The CCC fee code is $0277-786 \mathrm{X} / 12 / \$ 18.00$.

Printed in the United States of America.

Publication of record for individual papers is online in the SPIE Digital Library.

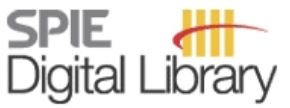

SPIEDigitalLibrary.org

Paper Numbering: Proceedings of SPIE follow an e-First publication model, with papers published first online and then in print and on CD-ROM. Papers are published as they are submitted and meet publication criteria. A unique, consistent, permanent citation identifier (CID) number is assigned to each article at the time of the first publication. Utilization of CIDs allows articles to be fully citable as soon as they are published online, and connects the same identifier to all online, print, and electronic versions of the publication. SPIE uses a six-digit CID article numbering system in which:

- The first four digits correspond to the SPIE volume number.

- The last two digits indicate publication order within the volume using a Base 36 numbering system employing both numerals and letters. These two-number sets start with 00, 01, 02, 03, 04, $05,06,07,08,09,0 A, 0 B \ldots 0 Z$, followed by 10-1Z, 20-2Z, etc.

The CID number appears on each page of the manuscript. The complete citation is used on the first page, and an abbreviated version on subsequent pages. Numbers in the index correspond to the last two digits of the six-digit CID number. 


\section{Contents}

$\begin{array}{ll}\text { xiii Conference Committee } \\ x v & \text { Introduction }\end{array}$

IMAGE PROCESSING

834902 Improved ISOMAP algorithm for anomaly detection in hyperspectral images [8349-09]

L. Wang, Z. Li, J. Sun, National Univ. of Defense Technology (China)

834903 Ontology development for Sufism domain [8349-12]

R. Iqbal, Karachi Institute of Economics and Technology (Pakistan)

834904 The simple-discernibility matrix in rough sets [8349-13]

S. Deng, M. Li, Nanchang Institute of Technology (China)

834905 Call-graph-based inter-class MM path generation [8349-14]

W. He, R. Zhao, Beijing Univ. of Chemical Technology (China)

834906 The design of moral education website for college students based on ASP.NET [8349-18] C. Sui, R. Du, Tangshan Normal Univ. (China)

834907 A user context utilization approach in keyword based web service discovery [8349-41] Q. Liu, X. Huang, Tongji Univ. (China)

834908 Research and implementation of video image acquisition and processing based on Java and JMF [8349-42]

J. Qin, Z. Li, Y. Niu, North China Electric Power Univ. (China)

834909 A novel duplicate images detection method based on PLSA model [8349-43]

$X$. Liao, Institute of Software (China), Graduate Univ. of the Chinese Academy of Sciences (China), and Nanchang Univ. (China); Y. Wang, L. Ding, Institute of Software (China); J. Gu, Ministry of Public Security (China)

8349 OA Image denoising by block-matching and ID filtering [8349-55]

Y. Hou, T. Chen, D. Yang, L. Zhu, H. Yang, Taishan Univ. (China)

8349 OB A novel multi-level segmentation method on oil spill of SAR image [8349-56]

Y. Guo, X. Wang, Shanghai Maritime Univ. (China)

8349 OC Research on projective distortion self-corrected photogrammetry [8349-58]

Z. Wang, Z. Lei, X. Ding, J. Gao, H. Li, Xi'an Technological Univ. (China)

8349 OD Eye and mouth localization for various imaging conditions images (Invited Paper) [8349-61] M. Hanafi, Imperial College London (United Kingdom) and Univ. Putra Malaysia (Malaysia); M. Petrou, Imperial College London (United Kingdom); A. R. Ramli, W. A. W. Adnan, Univ. Putra Malaysia (Malaysia) 
$8349 \mathrm{OE}$ Infrared and visible image registration using feature and area for image fusion [8349-65] X. Zhang, H. Qin, M. Wang, Leshan Normal Univ. (China); J. Yang, Leshan Public Security Bureau (China)

8349 OF A POCS super-resolution image reconstruction based on the projection residue [8349-69] Z. Luo, J. Wu, Nanchang Univ. (China)

8349 OG Design and development of LED-based irregular leather area measuring machine [8349-74] R. Adil, Karachi Institute of Economics and Technology (Pakistan); S. J. Khan, VectraCom (Pvt) Ltd. (Pakistan)

$8349 \mathrm{OH} \quad$ A marked bounding box method for image data reduction and reconstruction of sole patterns [8349-77]

X. Wang, J. Wu, Q. Zhao, Nanchang Univ. (China); J. Cheng, Y. Zhu, Jiangxi Provincial Public Security Bureau (China)

8349 Ol A novel multiple cues based image fusing algorithm for high dynamic range image generation [8349-81]

X. Wu, Shenzhen Institutes of Advanced Technology (China) and Harbin Institute of Technology (China); Z. Song, Shenzhen Institutes of Advanced Technology (China) and The Chinese Univ. of Hong Kong (Hong Kong, China); G. Yu, Harbin Institute of Technology (China); F. Zheng, Shenzhen Institutes of Advanced Technology (China) and The Chinese Univ. of Hong Kong (Hong Kong, China)

8349 0J Image denoising via combining contourlet and stationary-wavelet transform [8349-82] X. Song, D. Yamg, X. Qi, Xi'an Communication Institute (China)

8349 OK Smooth connection method of segment test data in road surface profile measurement [8349-88]

H.-M. Duan, China Automotive Engineering Research Institute (China) and Tongji Univ. (China); Y. Ma, F. Shi, K.-B. Zhang, F. Xie, China Automotive Engineering Research Institute (China)

8349 OL Fast line drawing algorithm by circular subtraction based on Bresenham [8349-101] X. Li, X. Shao, Zhengzhou Institute of Aeronautical Industry Management (China)

8349 OM Research of image retrieval system framework based on ontology and content [8349-106] H. Liu, Zhejiang Gongshang Univ. (China)

8349 ON The review of digital image border detection [8349-119] W. Fang, Hubei Univ. of Education (China); W. Zhang, Fiberhome Telecommunication Technologies Co., Ltd. (China)

834900 A fuzzy optimal threshold technique for medical images [8349-121]

B. Thirupathi Kannan, Anna Univ. (India); K. Krishnasamy, Sri S. Ramaswamy Naidu Memorial College (India); P. K. K. S., Infant Jesus College of Engineering and Technology (India)

8349 OP Ghost removal for background subtraction using color similarity comparison [8349-131] Z. Kadim, K. M. Liang, N. Samudin, K. M. Johari, H. W. Hon, MIMOS Berhad (Malaysia) 
$8349 \mathrm{OQ} \quad$ Variational motion segmentation based on discontinuity-preserving optical flow estimation [8349-133]

B. Dai, Y. Fang, J. Song, National Univ. of Defense Technology (China)

8349 OR Robust segmentation of color image for wireless applications [8349-136]

B. Bhattacharyya, B. Mandal, T. Mukhopadhyay, Visva-Bharati Univ. (India)

8349 OS Neural network-based brain tissue segmentation in MR images using extracted features from intraframe coding in H.264 [8349-156]

M. Jafari, Islamic Azad Univ. (Iran, Islamic Republic of); S. Kasaei, Sharif Univ. of Technology (Iran, Islamic Republic of)

8349 0T Analyzing the medical image by using clustering algorithms through segmentation process [8349-174]

P. Kumar, S. Kumar, Govind Ballabh Pant Engineering College (India)

8349 OU Research on birefringence of asymmetric photonic crystal fiber [8349-179]

M. Liu, Shijiazhuang Institute of Railway Technology (China) and Handon College (China);

Y. Li, Handan College (China); Y. Yue, Hebei Univ. of Technology (China)

\section{MACHINE VISION}

8349 OV A robust human face detection algorithm (Invited Paper) [8349-02]

T. Raviteja, S. Karanam, D. R. V. Yeduguru, National Institute of Technology, Warangal (India)

8349 OW Applying local Gabor ternary pattern for video-based illumination variable face recognition [8349-16]

H. Wang, Y. Han, Z. Zhang, Beihang Univ. (China)

8349 OX A swarm intelligence based memetic algorithm for task allocation in distributed systems [8349-19]

R. Sarvizadeh, M. Haghi Kashani, Islamic Azad Univ. (Iran, Islamic Republic of)

8349 OY Object-oriented MSVL and its application [8349-24]

X. Wang, Z. Duan, C. Tian, H. Zhang, Xidian Univ. (China)

$83490 Z$ A new hybrid genetic algorithm and its application in the RCPSP [8349-32]

Z. Li, J. Qin, North China Electric Power Univ. (China)

834910 EOTAS dynamic scheduling method based on wearable man-machine synergy [8349-33] Z. Liu, Hebei Institute of Mechanical and Electronic Technology (China); D. Wang, Xingtai Polytechnic College (China); Y. Yang, J. Zhao, Hebei Institute of Mechanical and Electronic Technology (China)

834911 An improved anti-leech mechanism based on session identifier [8349-37] J. Zhang, T. Zhu, H. Zhang, L. Lin, Beijing Univ. of Technology (China)

834912 JMF-based video monitoring system for power station equipment [8349-38]

J. Qin, Z. Li, Y. Niu, North China Electric Power Univ. (China) 
834913 Video auto stitching in multicamera surveillance system [8349-45]

B. He, G. Zhao, Q. Liu, Y. Li, Huazhong Normal Univ. (China)

834914 The analysis of network transmission method for welding robot information [8349-54]

W. Cheng, H. Zhang, D. Liu, H. Wang, Nanchang Univ. (China)

834915 Robust object tracking using camshift with multicue integration [8349-59]

Y. Zhong, S. Zhang, Jiangxi Univ. of Science and Technology (China)

834916 License plate location based on improved visual attention model [8349-60]

Z. Yao, W. Yi, Graduate Univ. of the Chinese Academy of Sciences (China)

834917 Face verification system based on texture feature with single sample per person [8349-63]

X. Wang, W. Yang, Q. Liao, Tsinghua Univ. (China)

834918 Design and implementation of signal processing scheme in CDMA wireless location systems [8349-66]

T. Yang, H. Fu, Henan Univ. of Technology (China)

834919 GDRMS: a system for automatic extraction of the disease-centre relation [8349-72]

R. Yang, Y. Zhang, L. Gong, Huaiyin Institute of Technology (China)

8349 IA Research on virtualization-based video-on-demand services architecture [8349-80]

C. Shu, X. Zhang, South China Univ. of Technology (China)

8349 1B An effective one-dimensional anisotropic fingerprint enhancement algorithm [8349-83]

Z. Ye, M. Xie, Univ. of Electronic Science and Technology of China (China)

8349 1C Gear visual inspection system and application in logarithmic spiral bevel gear [8349-89] Q. Li, Inner Mongolia Univ. of Science and Technology (China); Y. Liu, Sichuan Agricultural Univ. (China); H. Yan, Inner Mongolia Univ. of Science and Technology (China)

8349 ID Fusion of inertial and vision data for accurate tracking [8349-90]

J. Chen, W. Liu, Y. Wang, J. Guo, Beijing Institute of Technology (China)

8349 IE Handwritten Uighur character segmentation and performance evaluation [8349-92]

J. Li, Z. Lu, Xidian Univ. (China); A. Yimiti, Xidian Univ. (China) and Xinjiang Normal Univ. (China); F. Tan, Xidian Univ. (China)

8349 IF Identity-based group key exchange protocols resistant to colluding attacks [8349-93] Y. Jiang, Qujing Normal Univ. (China)

8349 1G Usife: a user space file system with support for intra-file encryption [8349-99] R. Sharma, P. Kallurkar, S. Kumar, S. R. Sarangi, Indian Institute of Technology Delhi (India)

$8349 \mathrm{1H}$ Fault diagnosis based on signed directed graph and support vector machine [8349-100] X. Han, Q. Lv, G. Xie, J. Zheng, Taiyuan Univ. of Technology (China)

$834911 \quad$ Extension of analog network coding in wireless information exchange [8349-108]

C. Chen, J. Huang, Huazhong Univ. of Science and Technology (China) 
8349 1 J Research on fault-relating pattern of mechanical system based on cellular automata [8349-112]

Y. Gao, X. Zhao, Yangzhou Polytechnic College (China)

$83491 \mathrm{~K} \quad$ Engineering application based on fuzzy approach [8349-1 16]

M. Pislaru, S. Avasilcai, A. Trandabat, Gheorghe Asachi Technical Univ. of Iaşi (Romania)

$83491 \mathrm{~L} \quad$ Visualization of OWL DL using ORM [8349-117]

W. Pan, D. Liu, Harbin Engineering Univ. (China)

$83491 \mathrm{M} \quad$ Using virtual machine monitors to overcome the challenges of monitoring and managing virtualized cloud infrastructures [8349-118]

M. A. Bamiah, S. N. Brohi, S. Chuprat, Univ. Teknologi Malaysia (Malaysia)

8349 IN Fuzzy regularized linear discriminant analysis for face recognition [8349-122]

M. Aghaei Taghlidabad, N. Baseri Salehi, International Sharif Univ. of Technology (Iran,

Islamic Republic of); S. Kasaei, Sharif Univ. of Technology (Iran, Islamic Republic of)

834910 High precision and convenient extension simulation platform for satellite attitude and orbit system [8349-123]

H. Cui, C. Han, P. Chen, Q. Luo, Beihang Univ. (China)

8349 1P Detection of navigation route in greenhouse environment with machine vision [8349-125]

H. Wang, C. Ji, Q. An, Q. Ding, Nanjing Agricultural Univ. (China)

$83491 Q \quad$ Employing grayscale fonts with equivalent luminance of background colours to discourage grayscale photocopying [8349-129]

H.-C. Soong, Univ. Tunku Abdul Rahman (Malaysia)

8349 1R Developing capacitive equipment on-line monitoring intelligence software [8349-138]

W. Zhang, L. Yang, Zhejiang Wanli Univ. (China)

8349 is A practical real-time detection visual system for driver's eye closure state tracking [8349-143]

T. Zhan, Z. Li, J. Zhang, Guangdong Polytechnic Normal Univ. (China)

8349 1T MIYAESI: leveraging Java sound programming interface for automatic music transcription [8349-147]

H. Abeykoon, T. Kaushalya, N. Akram, A. Dissanayaka, S. Weerawarana, C. De Silva, Univ. of Moratuwa (Sri Lanka)

$83491 \mathrm{U}$ Restoration of face images [8349-149]

A. Srinivasan, Sri Venkateswara College of Engineering (India)

$83491 \mathrm{~V}$ The flexible grinding technology based on the electric current control [8349-151]

L. Peng, B. Yao, F. Li, X. Wang, Xiamen Univ. (China); B. Yao, Shaanxi Hanjiang Machine Tool Co. Ltd. (China)

8349 IW The study of license plate location and character segmentation [8349-154]

Y. Lang, Y. Sun, Shenyang Aerospace Univ. (China) 
$83491 \mathrm{X} \quad$ Method of recognition and feature extraction about round and rectangular in mechanical process [8349-155]

D. Lu, C. Dai, Jiangsu Univ. of Science and Technology (China)

8349 1Y A framework of Chinese semantic text mining based on ontology learning [8349-162] Y. Zhang, Wuhan Univ. (China); F. Hu, Wuhan Univ. (China) and Guangdong Univ. of Technology (China)

834912 Application of a neural network predictive control based on GGAP-RBF for the supercritical main steam [8349-166]

Y.-J. Li, Kunming Univ. (China) and Wuhan Univ. (China); Y. Fang, Wuhan Univ. (China); Q. Li, Naval Univ. of Engineering (China)

834920 Application of adaptive PID control based on RBF-NN for the supercritical main steam [8349-167]

Y.-J. Li, Kunming Univ. (China) and Wuhan Univ. (China); Y. Fang, Wuhan Univ. (China)

$834921 \quad$ Hybrid fuzzy regression with trapezoidal fuzzy data [8349-168]

T. Razzaghnia, S. Danesh, A. Maleki, Islamic Azad Univ. (Iran, Islamic Republic of)

834922 Detecting outliers in fuzzy regression analysis with asymmetric trapezoidal fuzzy data [8349-169]

A. Maleki, Islamic Azad Univ. (Iran, Islamic Republic of); E. Pasha, Teacher Training Univ. (Iran, Islamic Republic of); Gh. Yari, Iran Univ. of Science and Technology (Iran, Islamic Republic of); T. Razzaghnia, Islamic Azad Univ. (Iran, Islamic Republic of)

834923 Review of intelligent video surveillance with single camera [8349-170]

Y. Liu, J. Fan, D. Wang, Xi'an Univ. of Post and Telecommunications (China)

\section{PATTERN ANALYSIS}

834924 Influence of marine engine simulator training to marine engineer's competence [8349-06] P. Wang, X. Cheng, Q. Ma, X. Song, X. Liu, L. Wang, Shandong Jiaotong Univ. (China)

834925 Research of RFID middleware model with CEP based on SOA [8349-07]

Z. Wang, Z. Ma, Hefei Univ. of Technology (China)

834926 Design of single object model of software reuse framework [8349-08]

L. Yan, Jiangxi Blue Sky Univ. (China)

834927 The expansion of the definition of granular sets [8349-10]

S. Guan, Nanchang Institute of Technology (China)

834928 Improving the trust algorithm of information in semantic web [8349-17]

Z. Wan, J. Min, East China Jiao Tong Univ. (China)

834929 Formal analysis of ORM using OWL DL [8349-20]

W. Pan, D. Liu, Harbin Engineering Univ. (China) 
8349 2A Intelligent management system research and design based on MSComm and Winsock [8349-26]

L. Shi, H. He, Shanghai Second Polytechnic Univ. (China)

8349 2B Indemnificatory research on key services of survivable networks [8349-28]

X. Chen, J. Zhang, Transport Management Institute (China); P. Xu, Beijing Information Science and Technology Univ. (China)

8349 2C The phenomenon analysis of different blowing stages under high pressure air blowing the submarine main ballast tanks [8349-30]

H. Liu, J. Pu, Q. Li, Naval Univ. of Engineering (China)

8349 2D The expert system of double-stage involute cylindrical gear assistant design transmission system [8349-34]

Z. Zhang, J. Hu, Z. Yang, J. Zhang, D. Chen, C. Che, Wuhan Univ. of Technology (China)

$83492 \mathrm{E} \quad$ Study of tourist motivation to Guangzhou urban ecological parks [8349-39]

M. Li, F. Wang, South China Univ. of Technology (China)

$83492 \mathrm{~F} \quad$ Governor foot mechanism optimum design on high-speed printing press [8349-40]

R.-M. Fang, H. Chen, H. Zhang, Beijing Institute of Graphic Communication (China)

$83492 \mathrm{G} \quad$ Realization of texture synthesis algorithm based on mixed programming via COM [8349-47]

R. Qin, Y. Pu, D. Xu, Yunnan Univ. (China); H. Chen, Yunnan Normal Univ. (China)

$83492 \mathrm{H} \quad$ Positive solutions of singular integro-differential equations at resonance in Banach spaces [8349-53]

J. Cao, Hunan Institute of Engineering (China) and Central South Univ. (China); H. Chen, Central South Univ. (China)

$834921 \quad$ Augmenting the access grid using augmented reality [8349-57]

Y. Li, Tangshan Teachers College (China)

8349 2J A vertical handoff decision algorithm based on ARMA prediction model [8349-67]

R. Li, J. Shen, J. Chen, Q. Liu, Inner Mongolia Univ. (China)

$83492 \mathrm{~K}$ Evaluation of node importance based on topological potential in weighted complex networks [8349-71]

R. Sun, A. Mu, L. Li, M. Zhong, Sichuan Univ. (China)

8349 2L A concept for making EMO mobile [8349-73]

M. Kumar, Samsung India Software Operations Pvt. Ltd. (India)

$83492 \mathrm{M}$ Determining the optimal number and position of damping viscose (MR) in seismic vibration control of buildings to use genetic algorithms (fuzzy engineering application) [8349-79]

F. Hatami, Research Institute of Petroleum Industry (Iran, Islamic Republic of); E. Karimi, Azad Univ. (Iran, Islamic Republic of)

$83492 \mathrm{~N}$ Tropical cyclone center location based on Fisher discriminant and Chan-Vese model [8349-85]

W. Qiao, Y. Li, X. Wei, J. Shen, Shanghai Jiaotong Univ. (China) 
834920 A routing algorithm for industrial wireless network based on deterministic scheduling [8349-86]

H. Wang, Q. Liu, P. Wang, Z. Luo, Chongqing Univ. of Posts and Telecommunications (China)

8349 2P Gas demand forecasting by a new artificial intelligent algorithm [8349-87]

V. Khatibi.B, E. Khatibi, Islamic Azad Univ. (Iran, Islamic Republic of)

$83492 \mathrm{~S}$ Study on DFIG wind turbines control strategy for improving frequency response characteristics [8349-95]

D. Zhao, D. Wu, Y. Liu, Z. Zhou, North China Electric Power Univ. (China)

$83492 R \quad$ The establishment of the safety factors system of railway operation [8349-96]

Y. Wang, X. Xiao, W. Xie, Beijing Jiaotong Univ. (China)

834925 Study on application of production flow analysis in manufacturing enterprise based on fuzzy clustering algorithm [8349-98]

Y. Du, Xi'an Technological Univ. (China)

8349 2T Application safety enhancement model using self-checking with software enzymes [8349-102]

C. Subramaniam, A. Ravishankar, D. Gopal, D. Subramanian, Rajalakshmi Engineering College (India)

$83492 \mathrm{U} \quad$ Error bounded conic spline approximation for NC code [8349-103]

L. Shen, Graduate Univ. of the Chinese Academy of Sciences (China)

8349 2V Cutting force regression modeling approach for turning Hastelloy $\mathrm{X}$ alloy by genetic algorithms [8349-104]

C. YU, J. Guo, Y. Zhang, J. Li, Shenyang Aerospace Univ. (China)

8349 2W A comparison of clustering algorithms in article recommendation system [8349-105]

S. Tantanasiriwong, Asian Institute of Technology (Thailand)

$83492 X \quad$ Research on infrared properties modeling and image generation of aircraft [8349-107]

N. Li, D. Han, Beihang Univ. (China)

8349 2Y XML-based product information processing method for product design [8349-1 10]

Z. Y. Zhang, Zhejiang Univ. of Science and Technology (China)

$83492 Z$ Fuzzy tool for conceptual modeling under uncertainty (Invited Paper) [8349-111]

B. Walek, C. Klimes, Univ. of Ostrava (Czech Republic)

834930 Research on the factors of return on equity: empirical analysis in Chinese port industries from 2000-2008 [8349-1 13]

W. Li, Dalian Maritime Univ. (China)

834931 The abstract model of dynamic evolution based on services [8349-115]

Y. Qian, T. Li, Y. Li, H. Gu, Yunnan Univ. (China) 
834932 Research of data quality control based on quality grading [8349-126]

S. H. Liu, J. G. YU, Y. L. YU, Zhengzhou Institute of Aeronautical Industry Management (China)

834933 E-badge-based access control model [8349-127]

Y. Shi, Z. Si, Information Engineering Univ. (China)

834934 Design of a robust and adaptive fuzzy-logic-based power system stabilizer (RAFLPSS) for damping low frequency electromechanical oscillations [8349-128] M. Abdurrahim, Al Ghurair Univ. (United Arab Emirates); A. K. M., B.S. Abdurrahman Univ. of Science and Technology (India); A. A. Edriss, Al Ghurair Univ. (United Arab Emirates)

834935 Heartbeat-based error diagnosis framework for distributed embedded systems [8349-130] S. Mishra, P. M. Khilar, National Institute of Technology Rourkela (India)

834936 Accident patterns for construction-related workers: a cluster analysis [8349-132] C.-W. Liao, Y.-Y. Tyan, China Univ. of Technology (Taiwan)

834937 Development stage and monetization model of micro-blog in China [8349-134] T. XU, L. Sun, Y. Yang, H. Ma, Capital Univ. of Economics and Business (China)

834938 Stabilization ball and beam by fuzzy logic control strategy [8349-135] H. Asadi, A. Mohammadi, M. Oladazimi, Univ. of Malaya (Malaysia)

834939 Fuzzy-control-based five-step Li-ion battery charger by using AC impedance technique [8349-144]

H. Asadi, S. Hr. Aghay Kaboli, A. Mohammadi, M. Oladazimi, Univ. of Malaya (Malaysia)

8349 3A DTMF-based pH-COP system [8349-145]

M. F. Shakila, P. Miriyala Premnath, R.M.D. Engineering College (India)

8349 3B Design and development of the mobile game based on the J2ME technology [8349-150] J. He, Huangshi Institute of Technology (China)

8349 3C Modeling and optimizing electrodischarge machine process (EDM) with an approach based on genetic algorithm [8349-157]

I. Zabbah, Islamic Azad Univ. (Iran, Islamic Republic of)

8349 3D A genetic algorithm for replica server placement [8349-158]

G. Eslami, A. Toroghi Haghighat, Qazvin Azad Univ. (Iran, Islamic Republic of)

8349 3E Fuzzy based power factor improvement strategy for a multiple connected AC-DC converter fed drive [8349-159]

R. N., R. Muthiah, Annamalai Univ. (India)

8349 3F Efficient indexing and searching framework for unstructured data [8349-160]

K. N. Aye, N. L. Thein, Univ. of Computer Studies, Yangon (Myanmar)

834936 An application of ranking function of fuzzy numbers to solve fuzzy revised simplex algorithm and fuzzy decomposition algorithm [8349-163]

M. Rostamy-Malkhalifeh, Islamic Azad Univ. (Iran, Islamic Republic of); H. Farajollahi, Teacher Training Univ. (Iran, Islamic Republic of) 
$83493 \mathrm{H} \quad$ Longest jobs first algorithm in solving job shop scheduling using adaptive genetic algorithm (GA) [8349-164]

V. Alizadeh Sahzabi, I. Karimi, N. Alizadeh Sahzabi, P. Mamaani Barnaghi, Islamic Azad Univ. (Iran, Islamic Republic of)

8349 31 Architecture for decision making in a home safety system [8349-172]

I. Uusitalo, M. Mantere, VTT Technical Research Ctr. of Finland (Finland)

8349 3J Data warehouse model design technology analysis and research [8349-175]

W. Jiang, Hangzhou Engineering Construction Quality and Safety Supervise Administration (China); Q. Li, Zhejiang Unv. of Technology (China)

8349 3K AgiSim: a simulator for real-time transaction scheduling and concurrency control [8349-176] J. Xu, H. Li, Graduate Univ. of Chinese Academy of Sciences (China); Q. Wang, Beijing Chinsoft Technology Co., Ltd. (China)

8349 3L Study on Chinese question classification based on SVM multi-category classification [8349-171]

W. Zhang, Shanxi Medical College for Continuing Education (China) and Taiyuan Univ. of Technology (China); L. Duan, J. Chen, Taiyuan Univ. of Technology (China)

8349 3M NBTI aware HLS using latches [8349-173]

R. Jangir, K. S. Yadav, Government Polytechnic Hisar (India) and NIIT, Delhi (India)

Author Index 


\title{
Conference Committee
}

\author{
Conference Chairs
}

Safaa S. Mahmoud, Ain Shams University (Egypt)

Shehroz S Khan, National University of Ireland, Galway (Ireland)

Program Committee Chairs

Nazar Zaki, United Arab Emirates University (United Arab Emirates)

Taweepol Suesut, King Monkut's Institute of Technology (Thailand)

Zhongwei Li, Huazhong University of Science and Technology (China)

Conference Steering Committee

Xuesong Zhang, Claremont Graduate University (United States)

S. M. Aqil Burney, University of Karachi (Pakistan)

Jun Guo, East China Normal University (China)

Selwyn Piramuthu, University of Florida (United States)

Organizing Chairs

Venkatesh Mahadevan, Swinburne University of Technology (Australia) Steve Thatcher, University of South Australia (Australia)

\section{Technical Committee}

M. S. Vijaya, GR Govindarajulu School of Applied Computer Technology (India)

Waleed Oransa, Arab Academy for Science and Technology (Egypt)

S. T. Gandhe, University of Mumbai (India)

Anton Satria Prabuwono, Universiti Teknologi Malaysia (Malaysia)

Taweepol Suesut, King Monkut's Institute of Technology (Thailand)

Vickneswaran Jeyabalan, Multimedia University (Malaysia)

Fa-quan Zhang, Zhengzhou University of Light Industry (China)

Rayner Alfred, Universiti Malaysia Sabah (Malaysia)

Kashif Zafar, National University of Computer and Emerging Science (Pakistan)

Garje G. V., Pune Vidyarthi Griha's College of Engineering and Technology (India) 
Proc. of SPIE Vol. $8349834901-14$

Downloaded From: https://www.spiedigitallibrary.org/conference-proceedings-of-spie on 25 Apr 2023 Terms of Use: https://www.spiedigitallibrary.org/terms-of-use 


\section{Introduction}

Dear Distinguished Delegates and Guests,

The Organizing Committee warmly welcomes our distinguished delegates and guests to the 2011 Fourth International Conference on Machine Vision (ICMV 201 1), held 9-10 December 2011 in Singapore.

The ICMV 2011 was organized by the Singapore Institute of Electronics (SIE) and cosponsored by the International Association of Computer Science and Information Technology (IACSIT). The ICMV 2011 was organized to gather members of our international community scientists so that researchers from around the world can present their leading-edge work, expanding our community's knowledge and insight into the significant challenges currently being addressed in that research. The conference program committee is itself quite diverse and truly international, with membership from the Americas, Europe, Asia, Africa and Oceania.

This proceedings volume records the fully refereed papers that were presented at the ICMV 2011. The main conference themes and tracks are machine vision. The main goal of these events is to provide international scientific forums for exchange of new ideas in a number of fields that interact in-depth through discussions with their peers from around the world. Both inward research; core areas of machine vision and outward research; multidisciplinary, interdisciplinary, and applications will be covered during these events.

The conference solicited and gathered technical research submissions related to all aspects of major conference themes and tracks. All of the submitted papers in these proceedings have been peer reviewed by the reviewers drawn from the scientific committee, external reviewers, and editorial board, depending on the subject matter of the paper. Reviewing and initial paper selection was undertaken electronically. After the rigorous peer-review process, the submitted papers were selected on the basis of originality, significance, and clarity for the purpose of the conference. The selected papers and additional late-breaking contributions presented as lectures made for an exciting technical program. The conference program was extremely rich, featuring high-impact presentations.

The high quality of the program - which was guaranteed by the presence of an unparalleled number of internationally recognized top experts - can be assessed when reading the contents of the program. The conference was therefore a unique event, where attendees appreciated the latest results in their field of expertise, and acquired additional knowledge in other fields. The program was structured to favor interactions among attendees coming from many diverse 
horizons, scientifically, geographically, from academia and from industry. Social events at prestigious sites favored interactions among the attendees.

We would like to thank the program chairs, organization staff, and the members of the program committees for their work.

We are grateful to all those who have contributed to the success of ICMV 2011. We hope that all participants and other interested readers benefit scientifically from these proceedings and also find it stimulating in the process. Finally, we would like to wish you success in your technical presentations and social networking.

We hope that you had a unique, rewarding, and enjoyable week at ICMV 2011 in Singapore.

With our warmest regards,

The Organizing Committees 9-10 December 2011 Singapore 